\title{
Domestication and Improvement in the Model C4 Grass, Setaria
}

\author{
Hao Hu, Margarita Mauro-Herrera and Andrew N. Doust* \\ Department of Plant Biology, Ecology, and Evolution, Oklahoma State University, Stillwater, OK, United States
}

\section{OPEN ACCESS}

Edited by:

Roberto Papa,

Università Politecnica delle Marche,

Italy

Reviewed by:

Karolina Susek,

Institute of Plant Genetics (PAN),

Poland

Matthew Nicholas Nelson,

Royal Botanic Gardens, Kew,

United Kingdom

${ }^{*}$ Correspondence:

Andrew N. Doust

andrew.doust@okstate.edu

Specialty section:

This article was submitted to

Plant Breeding,

a section of the journal

Frontiers in Plant Science

Received: 13 January 2018

Accepted: 14 May 2018

Published: 29 May 2018

Citation:

Hu H, Mauro-Herrera M and

Doust AN (2018) Domestication and Improvement in the Model C4

Grass, Setaria.

Front. Plant Sci. 9:719.

doi: 10.3389/fpls.2018.00719
Setaria viridis (green foxtail) and its domesticated relative $S$. italica (foxtail millet) are diploid C4 panicoid grasses that are being developed as model systems for studying grass genomics, genetics, development, and evolution. According to archeological evidence, foxtail millet was domesticated from green foxtail approximately 9,000 to 6,000 YBP in China. Under long-term human selection, domesticated foxtail millet developed many traits adapted to human cultivation and agricultural production. In comparison with its wild ancestor, foxtail millet has fewer vegetative branches, reduced grain shattering, delayed flowering time and less photoperiod sensitivity. Foxtail millet is the only present-day crop in the genus Setaria, although archeological records suggest that other species were domesticated and later abandoned in the last 10,000 years. We present an overview of domestication in foxtail millet, by reviewing recent studies on the genetic regulation of several domesticated traits in foxtail millet and discuss how the foxtail millet and green foxtail system could be further developed to both better understand its domestication history, and to provide more tools for future breeding efforts.

Keywords: Setaria, foxtail millet, genetic control, domestication, shattering, plant architecture, flowering time, photoperiod

\section{INTRODUCTION}

The evolution of human civilization is in many ways written on the back of grass domestication. Cereal grains directly or indirectly provide approximately half of the calories that support human populations (Emily et al., 2013). Furthermore, forage provided by both wild and improved grasses feed domesticated animal herds in much of the world. Grasses have also figured prominently in unraveling the domestication process and its relationship to evolution via natural selection (Doust, 2007a; Glemin and Bataillon, 2009). Despite this importance, differences in the details of domestication amongst the various lineages of grasses raise the question of whether there is a single model of domestication in the grasses or unique paths to similar phenotypes. Some phenotypes appear conserved (at least for cereal crops like rice, wheat, and maize), such as the change from a freely dispersed propagule to one that is hard to dislodge, and therefore reliably harvested from the plant ("non-shattering") (Purugganan and Fuller, 2009). However, even this change, which has the practical result of retaining seeds on the plant, appears to involve different combinations of floral and inflorescence parts, and be controlled by different genes in different domestication events (Doust et al., 2014b). In this context, it is worth considering whether increasing the number of cereal domestication events that we study can help us better understand underlying processes of domestication. Here, we use the term 'event' to signify an independent domestication, while recognizing that the process of domestication is not an instantaneous change from wild to domesticated forms (Allaby et al., 2017). In recent years, 
insights into the domestication process have increased rapidly, in part driven by the increased ease of genome sequencing. Rice (Oryza sativa)was the first sequenced grass genome (Goff et al., 2002; Yu et al., 2002; Matsumoto et al., 2005), followed by sorghum (Sorghum bicolor) (Paterson et al., 2009), Brachypodium (Vogel et al., 2010), maize (Zea mays) (Schnable et al., 2009), and various others, including foxtail millet (Setaria italica) (Bennetzen et al., 2012; Zhang et al., 2012), pearl millet (Pennisetum glaucum) (Varshney et al., 2017), Oropetium (VanBuren et al., 2015), and Dichanthelium (Studer et al., 2016). A new wave of investigation has recently started to target the wild progenitors of crop species, including the ancestor of maize, teosinte, and several ancestors of wheat (Jia et al., 2013a; Ling et al., 2013; Yang et al., 2017). These resources are providing new insights into domestication, and new opportunities for selection and improvement of under-utilized grain crops.

Foxtail millet (S. italica) is an ancient cereal grain crop of Northern China, that was grown in rotation with winter wheat in the regions around the Yellow River (Diao and Jia, 2017b). It is now grown in China, India, and Africa, excelling as a drought and low nutrient tolerant grain (Goron and Raizada, 2015; Nadeem et al., 2018). Its wild ancestor, green foxtail (S. viridis), is a widespread weed of temperate regions worldwide (Dekker, 2003). Foxtail millet principally differs from green foxtail in reduced vegetative branching, greater height, increased inflorescence branching, and larger seeds (Figure 1). Draft genomes are now available for both foxtail millet (S. italica) and its wild ancestor, green foxtail (S. viridis) (Setaria viridis v1.1, DOE-JGI ${ }^{1}$ ).

The genus Setaria belongs to the subtribe Cenchrinae and tribe Paniceae within the subfamily Panicoideae (Kellogg, 2017). All species possess the C4 photosynthetic pathway, and close relatives include pearl millet (formerly Pennisetum glaucum, now Cenchrus glaucum), (Chemisquy et al., 2010), napier grass (C. purpureum), and switchgrass (Panicum virgatum). The sister tribe is the Andropogoneae, which includes the important crop species maize (Z. mays), sorghum (Sorghum bicolor), and sugar cane (Saccharum officinarum) (Doust et al., 2009). Setaria is the largest genus in the Cenchrinae, and consists of approximately 100 species that are widely distributed in warm and temperate regions worldwide (Kellogg, 2017). The known domesticated crops in this genus include foxtail millet, yellow foxtail (S. pumila), and plains bristle grass (S. macrostachya), but foxtail millet is the only one that remains a major crop (Austin, 2006; Diao and Jia, 2017b). Other members of the genus, including green foxtail, are invasive weeds in corn and soybean field in many parts of the world (Dekker, 2003; Darmency et al., 2017). Besides Setaria and Cenchrus, the Cenchrinae clade also includes several smaller genera whose evolutionary relationships are not well understood (Doust et al., 2007; Kellogg, 2015, 2017). The relationships of foxtail millet and its wild progenitor, green foxtail, with respect to other species in the genus are unclear, as all studies to date have shown Setaria to be either paraor polyphyletic, depending on its circumscription (Doust et al., 2007; Kellogg et al., 2009; Kellogg, 2015). However, foxtail millet and green foxtail belong to a small well-supported clade, along

${ }^{1}$ http://phytozome.jgi.doe.gov/ with the tetraploid species, S. verticillata and S. faberi (Wang et al., 2009). S. faberi is an allotetraploid, with both genomes closely related to green foxtail, whereas $S$. verticillata appears to have one genome related to green foxtail, and the other to more distantly related species (Kellogg et al., 2009; Layton and Kellogg, 2014; Kellogg, 2017). The clade appears to be Asian in origin, even though the three wild species are all now widely distributed weeds.

Genetic analyses on foxtail millet, which date from at least the 1930's, concentrated on the genetics of distinct phenotypes, such as spikelet-tipped bristles and purple bristles (Ayyangar et al., 1933). Experiments on crossing in foxtail millet were also performed, and the difficulties in crossing the small flowers of these inbreeding plants was first discussed (Li et al., 1935). Much breeding work continued in China over the years since that time (Diao and Jia, 2017a), but only a few population genetic and herbicide resistance papers were published in English until the end of the last century. These included investigations into the origin of domestication of foxtail millet, which used a variety of markers to test hypotheses of origins in Northern China, South Asia, and the hypothesis of twin origins, in both China and Europe (Kawase and Sakamoto, 1984; Jusuf and Pernes, 1985; Darmency et al., 1987; Wang et al., 1995b; Fukunaga et al., 1997; Li et al., 1998; Nakayama et al., 1998; Le Thierry d'Ennequin et al., 2000). More recently, comparative genomic studies used common SSR markers to infer syntenic relationships between multiple grass genomes, including foxtail millet (Wang et al., 1998), and showed how the nine chromosomes of Setaria are simple rearrangements of the twelve chromosomes of rice (Brutnell et al., 2015). In addition, the same mapping population used to create the genetic maps that were the basis of comparative genome analyses was later used to identify quantitative trait loci (QTL) underlying phenotypic traits of both the vegetative body and inflorescence of Setaria (Doust et al., 2004, 2005; Doust and Kellogg, 2006). After the creation of advanced generation RILs, this population was also used to analyze the genetic determinants of traits such as branching (Mauro-Herrera and Doust, 2016; Doust, 2017), shattering (Doust et al., 2014a; Odonkor, 2015), height (Mauro-Herrera and Doust, 2016; Doust, 2017; Feldman et al., 2017), flowering time (Mauro-Herrera et al., 2013; Doust, 2017), and biomass (Mauro-Herrera et al., 2013; Mauro-Herrera and Doust, 2016; Doust, 2017; Feldman et al., 2017; Banan et al., 2018).

In 2012, the Setaria reference genome was independently released by two groups from the United States (Bennetzen et al., 2012) and China (Zhang et al., 2012). The United States group sequenced the foxtail millet inbred line Yugul using the Sanger platform, and generated a $396.7 \mathrm{Mb}$ assembly with $80 \%$ genome coverage and 35,158 annotated loci (Bennetzen et al., 2012). The Chinese group reported a genome from cultivated foxtail millet $\mathrm{cv}$. Zhanggu sequenced with the Illumina platform, producing a $\sim 423 \mathrm{Mb}$ draft that covered $\sim 86 \%$ of the total genome, with 38,801 genes annotated (Zhang et al., 2012). The genome assemblies allowed many more markers to be identified and denser linkage maps to be created, resulting in increased precision of QTL analysis (Kumari et al., 2013; Mauro-Herrera et al., 2013; Pandey et al., 2013; Zhang et al., 2014; Fang 

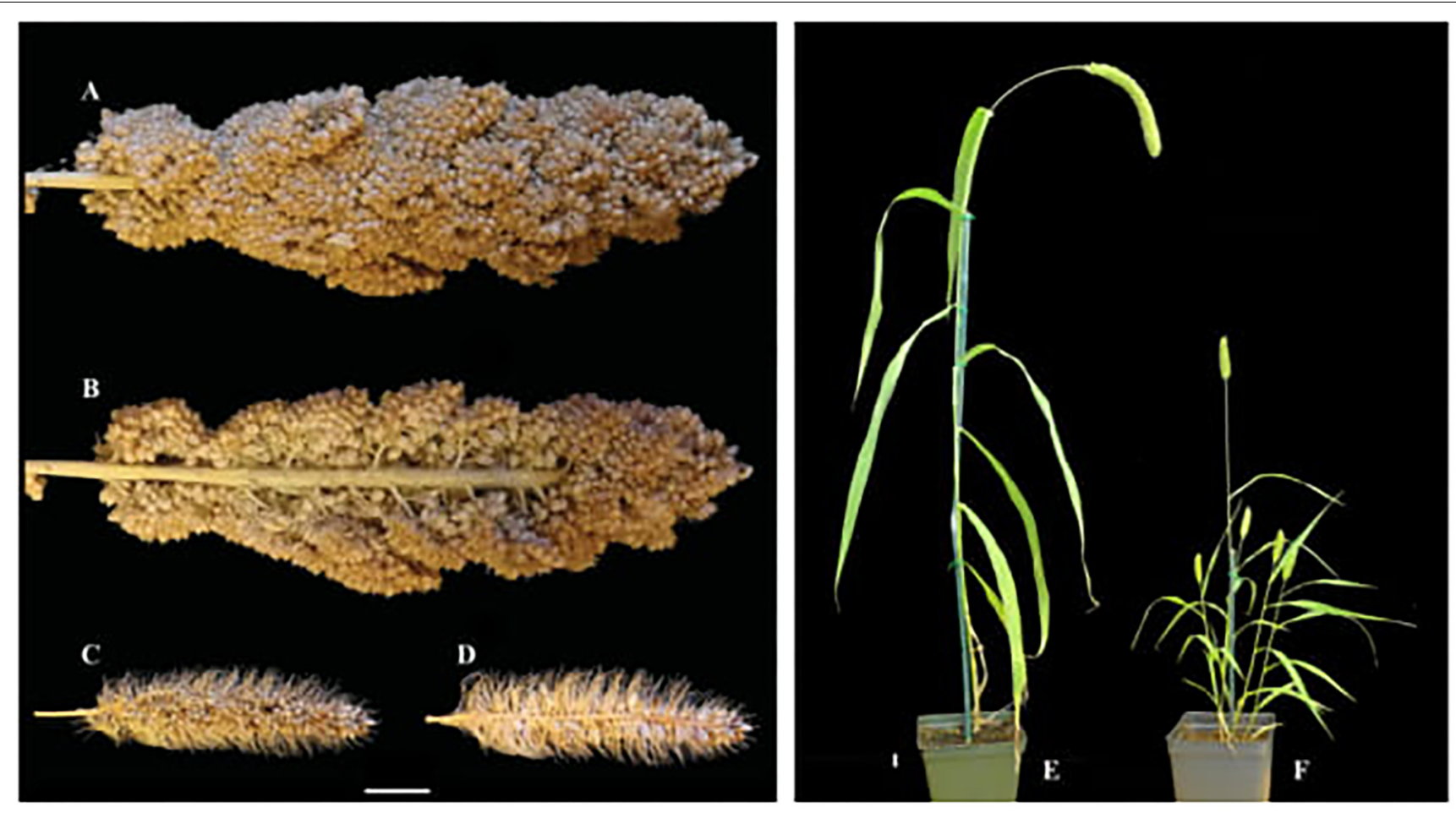

FIGURE 1 | Morphological comparison of domesticated foxtail millet and its wild ancestor green foxtail. Whole and longitudinal section of foxtail millet (A,B) and green foxtail (C,D) panicles. Whole plant of foxtail millet $(\mathbf{E})$ and green foxtail $\mathbf{( F )}$.

et al., 2016; Mauro-Herrera and Doust, 2016). Further reduced representation sequencing has also allowed dense marker maps to be generated for mapping populations (Fahlgren et al., 2015; Feldman et al., 2017). The genome sequence of the wild parent, green foxtail, of the Wang et al. (1998) mapping population is available (acc. A10.1), although there is as yet no publicly available genome for the foxtail millet accession, B100, the female parent of this population. Several other mapping populations have been created, both between foxtail millet and green foxtail (Qie et al., 2014), and within foxtail millet (Zhang K. et al., 2017), although none of them have been used to directly address the genetic changes that occurred during domestication.

In the last 10 years, the Setaria system (comprising foxtail millet and its wild progenitor green foxtail) has been promoted as an experimental model system for studying grass genetics and biofuel production (Doust et al., 2009; Brutnell et al., 2010, 2015; Li and Brutnell, 2011) (Figure 1). Both species possess several significant advantages over related $\mathrm{C} 4$ panicoid grasses such as maize and sorghum, including short life cycle, small size, simple growth requirements and ease of transformation (Brutnell et al., 2010). Difficulties with making controlled crosses between accessions, owing to small size of the individual flowers, has been addressed successfully by both temperature and chemical interventions to kill pollen in the female parent (Jiang et al., 2013; Zhang H.Y. et al., 2017), and much work has also been done on overcoming seed dormancy issues (Sebastian et al., 2014; Brenner et al., 2015; Acharya et al., 2017). Following recommendations made at the First international Setaria Genetics Conference in
Beijing in 2014, we have adopted the name Setaria (capitalized, no italics) for this model system (foxtail millet and green foxtail) while Setaria (capitalized, italics) remains the correct form for the genus name (Diao et al., 2014; Doust and Diao, 2017).

\section{THE DOMESTICATION OF FOXTAIL MILLET}

The most recent evidence to date suggests that domestication of foxtail millet occurred between 9,000 and 6,000 YBP in China, before being brought west into Europe (Diao and Jia, 2017b). Other hypotheses have included origins in Europe and in west Asia (Jones, 2004; Nasu et al., 2007). A separate origin in Europe is based on the relatively early appearance of foxtail millet grains in the European archeological record (4,000-3,000 YBP) (Nasu et al., 2007), and genetic evidence that European foxtail millet genotypes are more closely related to co-occurring green foxtail genotypes than to foxtail millet from China (Le Thierry d'Ennequin et al., 2000). However, recent studies of the movement of starchy grains across Eurasia have concluded that movement can be much faster by trade than formerly assumed (Lightfoot et al., 2013), and that the close relationship of foxtail millet and green foxtail in Europe is likely the result of hybridization between foxtail millet and green foxtail in Europe (Le Thierry d'Ennequin et al., 2000; Austin, 2006). Beyond archeological evidence, a recent genomic study that sequenced 
916 foxtail millet accessions suggested a single domestication event of foxtail millet in China (Jia et al., 2013b). Green foxtail accessions in China show a strong relationship to Chinese foxtail millet accessions, indicative of continued gene flow after domestication. The Chinese green foxtail accessions are distinct from populations in North America, some of which apparently arrived there prior to European settlement (Huang et al., 2014; Huang and Feldman, 2017; Schroder et al., 2017).

A recent review of archeological finds from China suggests that the domestication and widespread adoption of foxtail millet in China involved three phases (Diao and Jia, 2017b). The first was the pre-domestication phase $(23,000$ to $9,000 \mathrm{YBP})$, where several archeological finds of plant starches and stone tools for processing green foxtail and/or foxtail millet seeds have been found (Yang et al., 2012; Jia et al., 2013b). However, intact grains have not been recovered for this phase. The second phase was that of domestication $(9,000$ to $6,000 \mathrm{YBP})$, where foxtail millet grains have been found in multiple archeological sites in northern China, especially in the Yellow River region (Lü et al., 2009). These finds indicate that foxtail millet was being cultivated as a food crop. The third phase was the expansion phase (after 6,000 YBP), a phase during which large quantities of foxtail millet grains have been found in hundreds of archeological sites, especially in southern and western China (Lü et al., 2005, 2014). The evidence from archeological sites in the expansion phase suggests that foxtail millet had spread to several major regions of ancient China, and that cultivation had become widespread. In addition, after 6,000 YBP, foxtail millet had quickly spread to other regions, and foxtail millet grains have been recovered from archeological sites from Eastern Siberia (5,550-4,050 YBP) (Sergusheva and Vostretsov, 2009), Korea (5,500 YBP) (Lee, 2011), and Japan (4,000 YBP) (Crawford, 1992).

\section{THE GENETICS OF DOMESTICATION}

Although green foxtail and foxtail millet are usually described as separate species (Austin, 2006), recent studies have increasingly led to the conclusion that foxtail millet is just a domesticated version of green foxtail (Doust et al., 2009). The genetic evidence includes both isozyme (Wang et al., 1995a) and DNA marker analyses (Wang et al., 1998; Hirano et al., 2011; Li et al., 2012). Wang et al. (2010), using 50 accessions of cultivated foxtail and 34 of green foxtail, determined that foxtail millet only contained 55\% of the diversity of green foxtail, and that domestication occurred in China approximately 8700 years ago. They did not find fixed differences between the cultivars and their wild relatives, but did find a high proportion of shared polymorphisms, particularly for the cultivars. On average, domesticated foxtail millet shared almost $75 \%$ of its polymorphisms with green foxtail, whereas the proportion for green foxtail was $36 \%$. Unique polymorphisms were present in both species, but were much less prevalent in cultivars than in the wild species. They suggested that the domestication bottleneck in foxtail millet was more severe than in maize, but slightly less than in rice. More recent studies, on Chinese and on two sets of North American collections, have provided new insights into the relationships and diversity of foxtail and green foxtail. The large degree of overlap found by Wang et al. (2010) in Chinese foxtail millet and green foxtail accessions may be due to their long shared history, as recent analyses of green foxtail accessions from North America, China, and other regions, found two main groups in North America, and a third group that was more foxtail millet-like, and to which all of the Chinese accessions belonged (Huang et al., 2014; Schroder et al., 2017). A recent sequence study of multiple varieties of foxtail millet identified selective sweeps between landrace and improved varieties indicative of selection after domestication, as well as regions of low diversity in all varieties, indicative of a domestication bottleneck (Jia et al., 2013c). Jia et al. (2013c) focused on a low-diversity region on chromosome 9 that contains the SH1 locus, whose orthologous locus in sorghum has been shown to control abscission of the grain (shattering) (Lin et al., 2012). Further analysis of the genetic signature of domestication is necessary to understand the extent to which domestication in foxtail millet is similar to processes in other cereal grains.

\section{GENES CONTRIBUTING TO DOMESTICATION-RELATED TRAITS}

The identification of genes responsible for domestication traits in Setaria is still in its early stages, although multiple studies have highlighted genomic regions which appear to harbor causal loci (Doust et al., 2004, 2005, 2017; Mauro-Herrera et al., 2013; Odonkor, 2015; Mauro-Herrera and Doust, 2016; Coelho et al., 2017; Feldman et al., 2017; Wang et al., 2017). Some of these also appear to colocate with regions controlling domestication or improvement traits in other species (Mauro-Herrera et al., 2013; Doust et al., 2014b). Conservation of genes responsible for domestication was first noted by Paterson et al. (1995), and may indicate a shared genetic mechanism for changes in traits between wild and domesticated species. However, Bennetzen et al. (2012) compared sequences of several candidate domestication genes, such as $Q, q S H 1, t b 1$, etc., between foxtail millet and green foxtail, and found no coding differences, suggesting that the domestication of foxtail millet involved either a different set of loci, or regulation mechanisms that were not obvious by simple sequence comparison. Further work has refined and extended these observations, and we discuss below the evidence for genetic control of several domestication and improvement phenotypes.

\section{Shattering}

Seed shattering, or seed dispersal, is the mechanism by which plants disperse seeds at maturity. However, it is an unfavorable trait for cereal crops in agricultural production, because it leads to reduction in harvesting and grain yield ( $\mathrm{Li}$ and Olsen, 2016). The loss of the seed-shattering habit is thought to be one of the most important events in seed crop domestication, and it is a critical feature that distinguishes modern crops from their wild progenitors ( $\mathrm{Li}$ and Olsen, 2016). In grasses, the position and method of seed shattering is regulated by where abscission zones are formed. An abscission zone (AZ) can be formed in a variety of positions on the pedicel of the spikelet or on subtending branches, but in Setaria is underneath the glumes, so that the whole spikelet, 
containing one seed, falls off as a unit (Doust et al., 2014b). Hodge and Kellogg (2016) studied the anatomy and histology of AZs in both green foxtail and foxtail millet, but, unlike sorghum, rice or barley, no notable lignification was observed in the AZ of Setaria. However, cellular staining identified subtle differences of cell size, orientation and arrangement between green foxtail and foxtail millet, particularly in the non-shattering foxtail millet line Yugu1. The tensile strength that is required to remove a spikelet from the pedicel is much lower in wild green foxtail than domesticated foxtail millet, and a discrete cup-shaped structure remains after dispersal of the grain. In foxtail millet, however, a force able to remove the grain from the inflorescence usually results in a break in the pedicel rather than in the abscission zone beneath the glumes (Doust et al., 2014a).

Doust et al. (2014a) evaluated seed shattering in an F7 RIL mapping population of Setaria, and identified two significant QTLs - one locus (QTL1) on chromosome 9 that contributes more than $35 \%$ of the phenotypic variation, and the other locus (QTL2) on chromosome 5 that is responsible for about $8 \%$ (Table 1). They also found that there was no significant genetic interaction between QTL1 and any other loci, including QTL2, whereas QTL2 shows epistatic interactions with several other genomic locations. QTL1 is syntenic to the region on sorghum chromosome 1 that contains the SH1 locus, identified as the major locus controlling shattering in that species (Lin et al., 2012). The same locus was also detected in an analysis of genome variability in 916 diverse foxtail millet varieties (Jia et al., 2013b), where an 855-bp indel in coding sequence was found when compared with green foxtail (Figure 2). In addition, all foxtail millet varieties show very low sequence diversity in this region when compared with the wild progenitor green foxtail. Odonkor (2015) identified the sorghum SH1 homologous in chromosome 9 as a candidate gene for seed shattering in foxtail millet, and suggested that a miniature inverted-repeat transposable element (MITE) insertion leads to the non-shattering phenotype in foxtail millet. These lines of evidence strongly suggest that the Setaria ortholog of the SH1 locus controls much of the shattering phenotype in and Setaria. The second QTL, QTL2, identified by Doust et al. (2014a), is overlapped by a region showing a strong selective sweep in the GWAS study by Jia et al. (2013b) (Figure 2). However, the selective sweep differentiates landrace and modern varieties, with greater diversity in landrace varieties, suggesting that QTL2 was selected upon after domestication and during the improvement of the crop. This region harbors the ortholog of $q S H 1$, a major seed shattering gene in rice. If the qSH1 homolog is confirmed as the causal gene in QTL2 it may suggest that it was selected upon during crop improvement rather than in the initial stages of domestication. Thus for shattering it is possible that there is a shared conserved genetic mechanism that spans multiple species.

\section{Plant Height}

Height is a trait that may be targeted by human selection during crop domestication and improvement, and there is significant variation in height in landrace varieties of foxtail millet, and within green foxtail accessions (Li and Yang, 2008; Chander et al., 2017a,b; Ghimire et al., 2018). Differences in height amongst landrace varieties may reflect both an ancestral increase in height took place as selection for losing unproductive tillers, followed by differentiation as farmers in different localities targeted height for a variety of reasons, including grain production and foraging. The GWAS analysis of 916 foxtail millet varieties by Jia et al. (2013b) documented genomic regions showing strong association with plant height on chromosomes 2,4 , and 6, while Fang et al. (2016) used an F2 population from a cross between two foxtail millet varieties, and found four height related QTLs on chromosomes 1, 3, 6, and 7. Recent studies on height in the F7 recombinant inbred line mapping population derived from that of Wang et al. (1998) identified major height-related QTLs on chromosomes 5, 7, and 9, with the effect of the different QTL being expressed at different developmental stages. Thus, for example, the QTL on chromosome 5 controls at least half of the variation in height at the seedling stage, but less variation at flowering and during seed maturation (Mauro-Herrera and Doust, 2016; Feldman et al., 2017). Only a few QTL overlap between the different studies (Figure 2), suggesting that both environmental and genotypic variation between trials contribute to differences in genetic regulation. The genes underlying these QTL have yet to be definitively isolated, but mapping efforts of several mutants are ongoing (Xue et al., 2016; Fan et al., 2017). The QTL regions also contain known candidate genes for height change, including, on chromosome $\mathrm{V}$, the ortholog of SEMIDWARF 1 (SD1), a gene that was important in breeding semi-dwarf rice varieties for the Green Revolution (Ashikari et al., 2002; Asano et al., 2011). Further work needs to be done to show that these genes actually control height, or to explain how different genes control height at different developmental stages.

\section{Plant Branching}

Vegetative branching significantly contributes to the determination of plant architecture (Doust, 2007a,b; McSteen, 2009; Hodge and Doust, 2017), and involves complicated genetic and environmental regulation (Finlayson et al., 2010). Humandirected selection and domestication has led to a dramatic reduction in vegetative branching in Setaria, presumably as a response to increased planting density and increases in seed weight and number of seeds per inflorescence (Doust, 2007a). Doust et al. (2004) reported the first QTL analysis of basal (tillering) and aerial branching in Setaria, and identified four QTLs for tillering on chromosomes 1, 3, and 4, and four QTLs for aerial branching on chromosomes 4, 5, and 9. Interestingly, the ortholog of $t b 1$, a major gene controlling branching in maize, was found to associate with only a minor QTL for branching in Setaria (Doust et al., 2004), as was also reported in the closely related species, pearl millet (Poncet et al., 2002). A further study of trials in different greenhouse conditions and between greenhouse and field trials revealed substantial genotype by environment $(\mathrm{G} \times \mathrm{E})$ relationships (Doust and Kellogg, 2006; Mauro-Herrera and Doust, 2016). Comparison with the GWAS analysis of 916 foxtail millet varieties by Jia et al. (2013b) showed several regions of overlap but also many unique QTL, emphasizing that branching has a high $\mathrm{G} \times \mathrm{E}$ component (Figure 2). 
TABLE 1 | Summary of published quantitative trait loci (QTLs) of key domestication traits in Setaria.

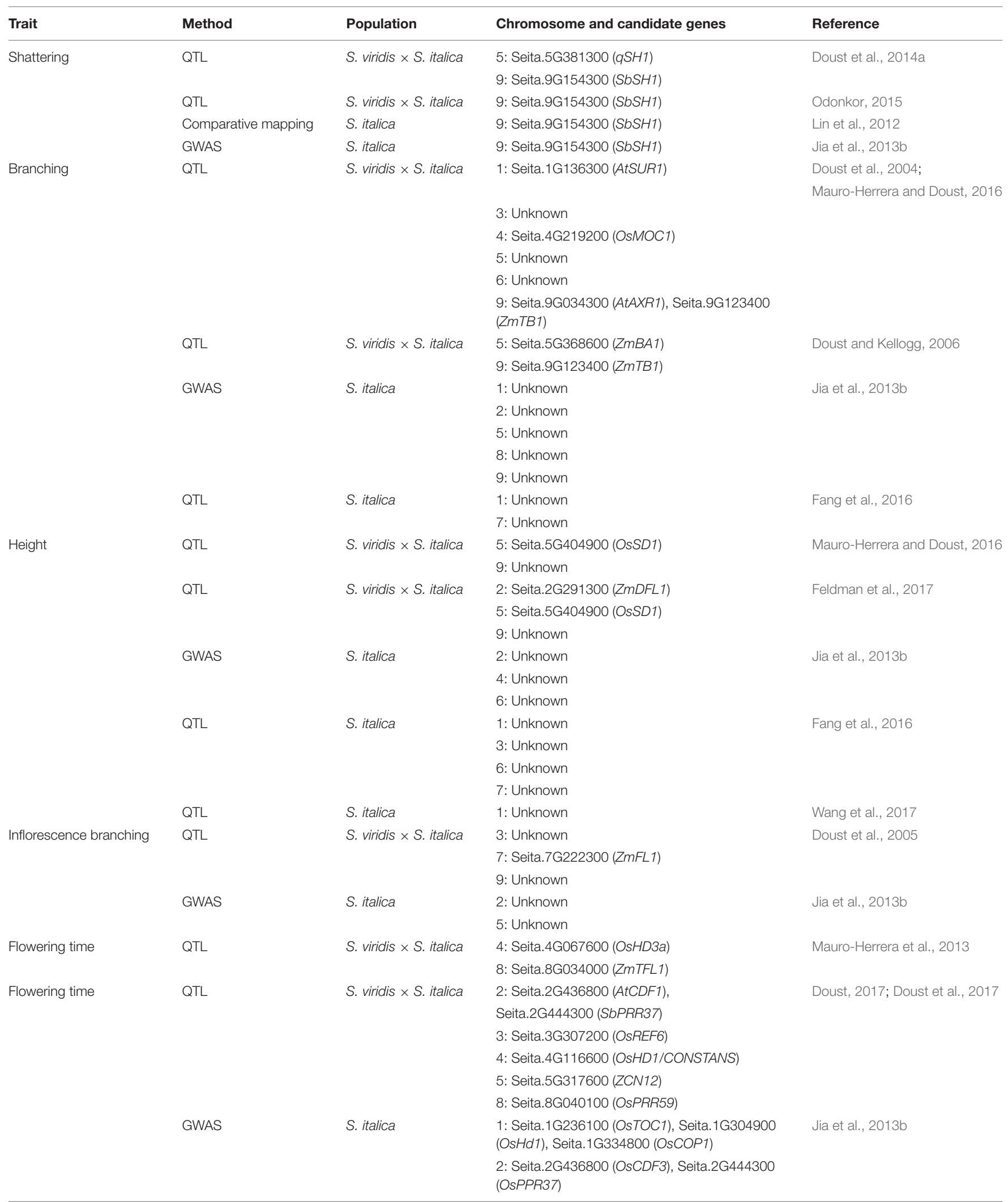


TABLE 1 | Continued

\begin{tabular}{|c|c|c|c|c|}
\hline Trait & Method & Population & Chromosome and candidate genes & Reference \\
\hline & & & 3: Seita.3G044600 (OsTOE1) & \\
\hline & & & 4: Seita.4G282900 (OsFD1) & \\
\hline & & & $\begin{array}{l}\text { 6: Seita.6G240100 (OsABF3), Seita.6G248900 } \\
\text { (OsSPY) }\end{array}$ & \\
\hline & & & $\begin{array}{l}\text { 7: Seita.7G007800 (OsP), Seita.7G119400 } \\
\text { (OsCRY1b) }\end{array}$ & \\
\hline & & & $\begin{array}{l}\text { 8: Seita.8G146800 (OsGF14d), } \\
\text { Seita.8G146900 (OsFKF1) }\end{array}$ & \\
\hline & & & 9: Seita.9G342700 (OsMADS56) & \\
\hline
\end{tabular}

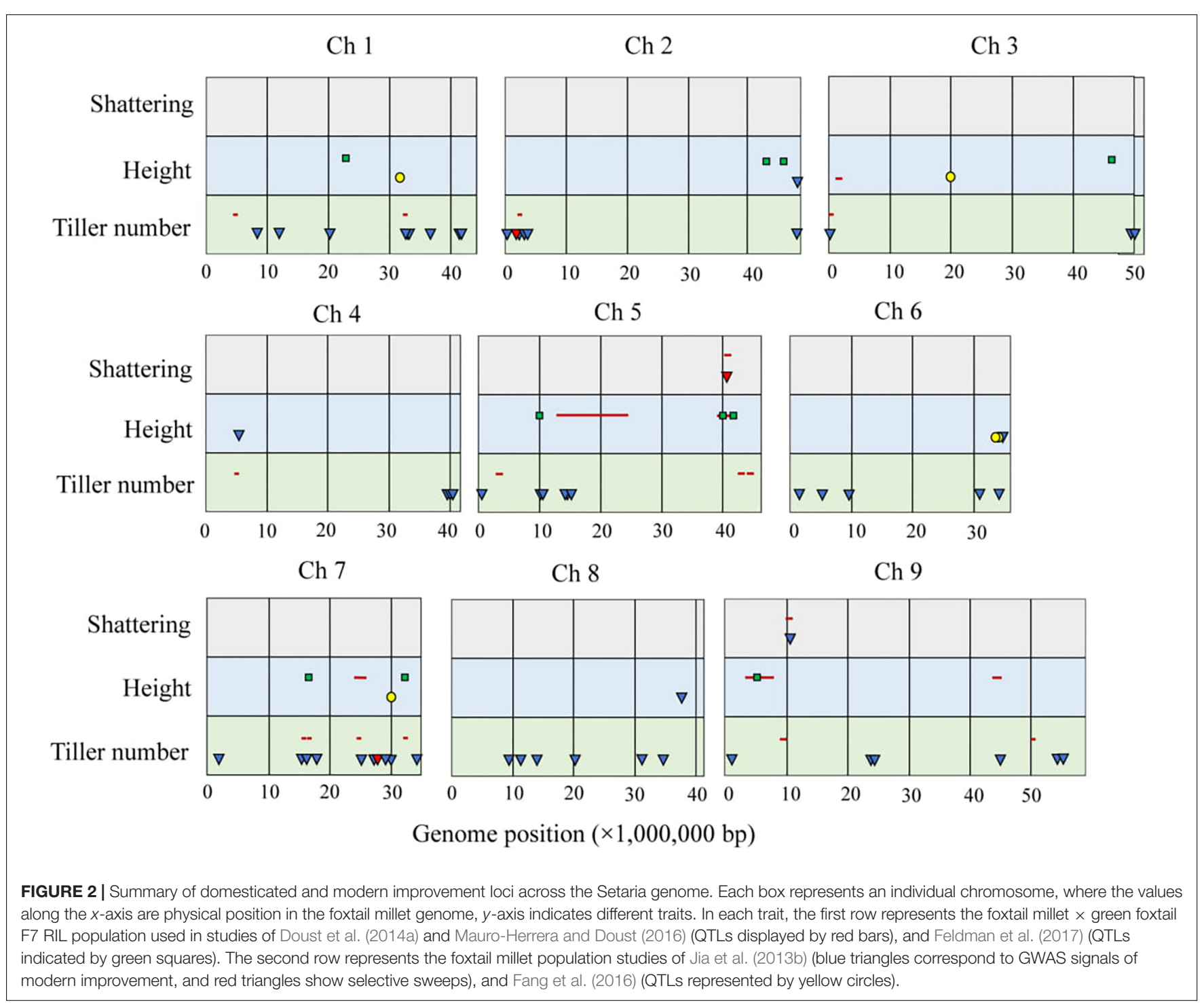

The size and branching architecture of the inflorescence (panicle) also directly affects yield, as it determines the number of grains per panicle and hence final grain yield. Foxtail millet and green foxtail differ in the number of orders of branching within the inflorescence (Figures 1A-D), and Doust et al. (2005) identified three QTL for primary branch number/density on chromosomes 3, 7, and 9, whilst Jia et al. (2013b) identified three GWAS associations of chromosomes 2 and 5 (Table 1). Several of the QTL identified for primary inflorescence branch number in Doust et al. (2005) overlapped with QTL identified for vegetative branching (Doust et al., 2004). Other studies have focused on traits 
indicative of total yield, including panicle length, diameter, and weight (Jia et al., 2013b; Wang et al., 2017; Zhang K. et al., 2017). However, few of these QTL overlap, suggesting multiple genes underlying these traits and/or environmental regulation. However, the latter seems surprising given the tight control over inflorescence form exhibited by plants, and it may be that present methods of analysis have not been able to satisfactorily decompose the inflorescence branch system in a way that can reveal underlying developmental drivers. An attempt to do this was done within the clade that Setaria belongs to (Doust and Kellogg, 2002), but a detailed analysis of inflorescence development in Setaria using emerging technologies such as X-ray tomography and other noninvasive techniques, along with new ways of analyzing data such as persistent homology analysis, remains to be accomplished (Bucksch et al., 2017).

\section{Flowering Time and Photoperiod Sensitivity}

Flowering is a critical indicator of the transition from vegetative growth to reproduction in the development of plants. The wild progenitors of crop species typically are photoperiod sensitive, because they are required to maximize their adaptability to their growing location. Crop species, on the other hand, may be selected for reduced photoperiod sensitivity in order to increase the range of localities in which they can be grown, and may have longer growing time, later flowering, and thus increased yield (Cockram et al., 2007). Thus selection on flowering time is unlikely to be a direct response to domestication but is best considered as a target for crop improvement. However, flowering time and photoperiod sensitivity also interact with other important traits, such as branching, height and biomass (Doust, 2017;Doust et al., 2017), making it relevant to discuss here.

Setaria has a wide latitudinal and longitudinal distribution around the world, and genetic evidence suggests that foxtail millet was domesticated from green foxtail in northern China, at temperate latitudes. Both foxtail millet and green foxtail show variation in photoperiod sensitivity (Swanton et al., 1999; Li and Yang, 2008; Jia et al., 2013b). In China, the four different growing regions are distinguished on the basis of spring or summer growing season and on variation in sensitivity to photoperiod and altitude (Diao and Jia, 2017a). Jia et al. (2013b) grew 916 accessions in four different latitudinal localities, and recorded differences in both morphology and heading date, along with differing significant SNP associations. A recent multiplexed shotgun genotyping (MSG) resequencing analysis of 439 RILs (derived from a cross between foxtail millet accessions Zhanggu and A2) under short ( $<12 \mathrm{~h}$ light) and long photoperiods ( $>14 \mathrm{~h}$ light), uncovered a total of 59 QTLs for 14 agronomic traits which were influenced by different photoperiods (Zhang K. et al., 2017). Doust et al. (2017) examined flowering responses in short (8 or $12 \mathrm{~h}$ light) and long (16 h light) photoperiods in a QTL mapping population, and demonstrated differences between short and long day regulation, with the 8 and $12 \mathrm{~h}$ photoperiods sharing QTL on chromosomes
4 and 5, and the 12 and $16 \mathrm{~h}$ having a shared QTL on chromosome 8. In addition there were QTLs on chromosomes 2 and 3 that were unique to the $16 \mathrm{~h}$ photoperiod. MauroHerrera et al. (2013) identified 16 flowering time QTLs across eight independent trials with varying climatic and photoperiod conditions, with domesticated foxtail millet alleles contributing to increased days to flowering. These QTL regions contained many candidate flowering genes identified from rice, maize, sorghum, and Arabidopsis, suggesting that the major genetic components in Setaria flowering and photoperiod response pathways are the same as in other plant species, even if the regulatory mechanisms are different between long and short day environments.

\section{PERSPECTIVES FOR FUTURE BREEDING}

Foxtail millet is well adapted to harsh environments, particularly under drought (Tang et al., 2017). It serves as an important staple grain in arid and semi-arid regions of Asia, particularly in northern China and India (Diao, 2017). The modern breeding programs of foxtail millet were initiated in the 1930s in India and 1950s in China, and were mostly focused on yield-related traits, because compared with other major crops, such as rice, wheat, and maize, the yield of foxtail millet is still relatively low (Diao and Jia, 2017a). However, global climate change, coupled with increasing population and reduction in arable lands, is adversely affecting cereal grain production in multiple regions (Wheeler and von Braun, 2013; Asseng et al., 2014). Stress tolerant foxtail millet is a potential crop that would be suitable for growing in drier and warmer conditions with few available inputs, particularly in developing countries in Asia and Africa (Huang et al., 2016).

There have been several studies exploring drought stress resistance traits in Setaria. Qie et al. (2014) investigated drought tolerance-related QTLs controlling germination and early seedling growth, using an F7 population of a cross between foxtail millet Yugu1 and green foxtail W53, and identified a total of 18 QTLs. Tang et al. (2017) compared the transcriptomes of drought-tolerant foxtail millet Yugu1 and drought-sensitive An04, and suggested that there was intense transcriptomic remodeling caused by genotype $\times$ drought stress interactions. Qi et al. (2013) studied differential gene expression patterns under PEG-induced drought treatment and found a total of 2,824 drought-responsive genes, including a large number of small RNAs and long non-coding RNAs that were actively involved in regulating drought-responsive genes. A dehydration-responsive element binding protein gene, SiDREB2 (Lata et al., 2011; Lata and Prasad, 2014) and an ABA-responsive DREB, SiARDP (Li et al., 2014), were found to contribute to drought tolerance in foxtail millet. Peng et al. (2010) reported that the overexpression of phospholipase D (PLD) from foxtail millet could enhance the drought tolerance in Arabidopsis by elevating the sensitivity to ABA. These studies suggest that there is much scope for future breeding of foxtail millet with enhanced drought tolerance that 
may provide new opportunities for increased food production in marginal crop production areas. Besides stress tolerance, other traits like resistance to leaf rust or blast diseases, and pests such as nematodes and other insects, are also important future breeding goals.

The traditional "phenotype-to-gene" forward genetics approach has been applied in the breeding and basic research of Setaria for many decades. Although several QTLs have been successfully identified from agronomically important traits, as reviewed above, the fine mapping of candidate genes is still challenging, mostly due to the lack of high density marker maps and high-quality reference genomes (Huang et al., 2016). However, the application of next generation sequencing in diverse collections of foxtail millet cultivars (Jia et al., 2013b) and wild green foxtail accessions (Huang and Feldman, 2017) are enabling the discovery of genomic variations on a large-scale. Meanwhile, the use of bulked segregant analysis (BSA) to quickly analyze mutant collections generated by chemical mutagenesis (Jiang et al., 2017) is accelerating Setaria gene discovery (Xue et al., 2016; Fan et al., 2017; Huang et al., 2017). New genes contributing to leaf color (Li et al., 2016), height, and inflorescence architecture (Masumoto et al., 2016; Huang et al., 2017; Xiang et al., 2017; Yang et al., 2018) have been successfully identified with this approach, substantially advancing our understanding of important traits.

In addition to forward genetics, transgenic-based reverse genetics tools are also being developed. Green foxtail can be easily transformed, unlike other panicoid model systems such as maize, sorghum, and Brachypodium, which are recalcitrant to transformation. Agrobacterium-mediated transformation methods starting with mature seeds have been successfully established (Van Eck et al., 2011, 2017; Van Eck and Swartwood, 2015), and faster floral-dip transformation methods have also been proposed (Martins et al., 2015; Saha and Blumwald, 2016, 2017). The rise of genome editing via CRISPR/Cas9 system will also enhance the future of Setaria genetics (Kikuchi et al., 2017; Zhu et al., 2017). The development of the Setaria genetic toolkit and resources will accelerate gene discovery and functional genomics analysis, benefiting not only millet breeding programs, but also enabling translational research from Setaria to other panicoid crops.

\section{CONCLUSION}

The Setaria system provides a window into domestication processes in the panicoid grasses that expands the discoveries

\section{REFERENCES}

Acharya, B. R., Choudhury, S. R., Estelle, A. B., Vijayakumar, A., Zhu, C. M., Hovis, L., et al. (2017). Optimization of phenotyping assays for the model monocot Setaria viridis. Front. Plant Sci. 8:2172. doi: 10.3389/fpls.2017.02172

Allaby, R. G., Stevens, C., Lucas, L., Maeda, O., and Fuller, D. Q. (2017). Geographic mosaics and changing rates of cereal domestication. Philos. Trans. R. Soc. B 372:20160429. doi: 10.1098/rstb.2016.0429 that have already been made in the major crops of sorghum and maize. Differences between foxtail millet and those crops include an experimentally amenable wild ancestor that is widespread in temperate latitudes of the world and a domestication process that occurred at temperate latitudes, meaning that selection during improvement for adaptation to temperate latitudes was likely less intense than for maize and sorghum. The evidence from the traits presented here is that some conservation of genetic programs for domestication is shared between Setaria and other grasses, although definitive studies are still lacking. However, the Setaria system is not yet fully developed, and there are several areas that could be improved for future studies. These include a great need for additional and larger mapping populations, especially multi-parental mapping populations that will increase the power to identify causal genes. This approach has been very powerful for the sorghum, maize, rice, and Arabidopsis communities (Buckler et al., 2009; Kover et al., 2009; McMullen et al., 2009; Bandillo et al., 2013; Holland, 2015; Ongom and Ejeta, 2017), and would be of undoubted value for Setaria. Availability of genetic resources is also an issue, as the great diversity within China is essentially unavailable to outside researchers. Therefore, studies on the full diversity of the crop, foxtail millet, are limited to Chinese researchers at this time. Fortunately, studies on North American green foxtail wild diversity reveal that much of the species diversity is found there (Huang et al., 2014; Huang and Feldman, 2017; Schroder et al., 2017), a finding that will be important for future researchers. Another important aspect of the Setaria system is the promise of easy transformability, although there is as yet no published reports of transformation being used to confirm gene function. Routine transformation methods, including the possibility of a successful floral dip protocol, will help propel Setaria into a powerful system for gene discovery, as well as illuminating its domestication history and enhancing its future potential as a crop for a changing world.

\section{AUTHOR CONTRIBUTIONS}

AD conceived the idea. $\mathrm{HH}$ and MM-H compiled genetic studies. $\mathrm{HH}, \mathrm{MM}-\mathrm{H}$, and AD interpreted the data, wrote, and revised the manuscript.

\section{FUNDING}

This research was supported by the Natural Science Foundation (NSF-IOS 1339332 and NSF-IOS 1557640 to AD).

Asano, K., Yamasaki, M., Takuno, S., Miura, K., Katagiri, S., Ito, T., et al. (2011). Artificial selection for a green revolution gene during japonica rice domestication. Proc. Natl. Acad. Sci. U.S.A. 108, 11034-11039. doi: 10.1073/ pnas.1019490108

Ashikari, M., Sasaki, A., Ueguchi-Tanaka, M., Itoh, H., Nishimura, A., Datta, S., et al. (2002). Loss-of-function of a rice gibberellin biosynthetic gene, GA20 oxidase (GA20ox-2), led to the rice 'green revolution'. Breed. Sci. 52, 143-150. doi: $10.1270 /$ jsbbs. 52.143 
Asseng, S., Ewert, F., Martre, P., Rötter, R. P., Lobell, D. B., Cammarano, D., et al. (2014). Rising temperatures reduce global wheat production. Nat. Clim. Change 5, 143-147. doi: 10.1038/nclimate2470

Austin, D. F. (2006). Fox-tail millets (Setaria: Poaceae) - abandoned food in two hemispheres. Econom. Bot. 60, 143-158. doi: 10.1663/0013-0001(2006)60[143: FMSPFI]2.0.CO;2

Ayyangar, G. N. R., Narayanan, T. R., and Rao, T. N. (1933). The inheritance of characters in Setaria italica (Beauv.), the Italian millet. Part IV. Spikelet-tipped bristles. Ind. J. Agric. Sci. 3, 552-558.

Banan, D., Paul, R. E., Feldman, M. J., Holmes, M. W., Schlake, H., Baxter, I., et al. (2018). High-fidelity detection of crop biomass quantitative trait loci from low-cost imaging in the field. Plant Direct 2:e00041. doi: 10.1002/ pld3.41

Bandillo, N., Raghavan, C., Muyco, P. A., Sevilla, M. A., Lobina, I. T., Dilla-Ermita, C. J., et al. (2013). Multi-parent advanced generation inter-cross (MAGIC) populations in rice: progress and potential for genetics research and breeding. Rice 6:11. doi: 10.1186/1939-8433-6-11

Bennetzen, J. L., Schmutz, J., Wang, H., Percifield, R., Hawkins, J., Pontaroli, A. C., et al. (2012). Reference genome sequence of the model plant Setaria. Nat. Biotechnol. 30, 555-561. doi: 10.1038/nbt.2196

Brenner, D. M., Dekker, J., Niemi, J., and Pfiffner, L. (2015). Medical oxygen concentrators for releasing seed dormancy. Crop Sci. 55, 2291-2293. doi: 10. 2135/cropsci2014.11.0783

Brutnell, T. P., Bennetzen, J. L., and Vogel, J. P. (2015). Brachypodium distachyon and Setaria viridis: model genetic systems for the grasses. Annu. Rev. Plant Biol. 66, 465-485. doi: 10.1146/annurev-arplant-042811-105528

Brutnell, T. P., Wang, L., Swartwood, K., Goldschmidt, A., Jackson, D., Zhu, X.G., et al. (2010). Setaria viridis: a model for C4 photosynthesis. Plant Cell 22, 2537-2544. doi: 10.1105/tpc.110.075309

Buckler, E. S., Holland, J. B., Bradbury, P. J., Acharya, C. B., Brown, P. J., Browne, C., et al. (2009). The genetic architecture of maize flowering time. Science 325, 714-718. doi: 10.1126/science.1174276

Bucksch, A., Atta-Boateng, A., Azihou, A. F., Battogtokh, D., Baumgartner, A., Binder, B. M., et al. (2017). Morphological plant modeling: unleashing geometric and topological potential within the plant sciences. Front. Plant Sci. 8:900. doi: 10.3389/fpls.2017.00900

Chander, S., Bhat, K. V., Gowda, M. V. C., and Dikshit, N. (2017a). Identification, characterization and validation of core collection of foxtail millet (Setaria italica). Ind. J. Agric. Sci. 87, 899-910.

Chander, S., Bhat, K. V., Kumari, R., Sen, S., Gaikwad, A. B., Gowda, M. V. C., et al. (2017b). Analysis of spatial distribution of genetic diversity and validation of Indian foxtail millet core collection. Physiol. Mol. Biol. Plants 23, 663-673. doi: 10.1007/s12298-017-0448-5

Chemisquy, M. A., Giussani, L. M., Scataglini, M. A., Kellogg, E. A., and Morrone, O. (2010). ). Phylogenetic studies favour the unification of Pennisetum, Cenchrus and Odontelytrum (Poaceae): a combined nuclear, plastid and morphological analysis, and nomenclatural combinations in Cenchrus. Ann. Bot. 106, 107-130. doi: 10.1093/aob/mcq090

Cockram, J., Jones, H., Leigh, F. J., O’sullivan, D., Powell, W., Laurie, D. A., et al. (2007). Control of flowering time in temperate cereals: genes, domestication, and sustainable productivity. J. Exp. Bot. 58, 1231-1244. doi: 10.1093/jxb/ erm042

Coelho, C., Huang, P., and Brutnell, T. P. (2017). Setaria viridis as a Model for C-4 Photosynthesis. Plant Cell 22, 2537-2544. doi: 10.1007/978-3-319-45105-3_17

Crawford, G. W. (1992). “The transitions to agriculture in Japan," in Transitions to Agriculture in Prehistory, eds A. B. Gebauer and T. D. Price (Madison, WI: Prehistory Press), 117-132.

Darmency, H., Wang, T., and Délye, C. (2017). "Herbicide resistance in Setaria," in Genetics and Genomics of Setaria, eds A. Doust and X. Diao (Cham: Springer International Publishing), 251-266. doi: 10.1007/978-3-319-45105-3_15

Darmency, H., Zangre, G. R., and Pernes, J. (1987). The wild-weed-crop complex in setaria - a hybridization study. Genetica 75, 103-107. doi: 10.1016/j.bbrc.2010. 02.068

Dekker, J. (2003). The foxtail (Setaria) species-group. Weed Sci. 51, 641-656. doi: 10.1614/P2002-IR

Diao, X., and Jia, G. (2017a). "Foxtail millet breeding in China," in Genetics and Genomics of Setaria, eds A. Doust and X. Diao (Cham: Springer International Publishing), 93-113. doi: 10.1007/978-3-319-45105-3_6
Diao, X., and Jia, G. (2017b). "Origin and domestication of foxtail millet," in Genetics and Genomics of Setaria, eds A. Doust and X. Diao (Cham: Springer International Publishing), 61-72. doi: 10.1007/978-3-319-45105-3_4

Diao, X., Schnable, J., Bennetzen, J. L., and Li, J. (2014). Initiation of Setaria as a model plant. Front. Agric. Sci. Eng. 1, 16-20. doi: 10.15302/J-FASE-2014011

Diao, X. M. (2017). Production and genetic improvement of minor cereals in China. Crop J. 5, 103-114. doi: 10.1093/mp/ssn039

Doust, A. (2007a). Architectural evolution and its implications for domestication in grasses. Ann. Bot. 100, 941-950.

Doust, A. N. (2007b). Grass architecture: genetic and environmental control of branching. Curr. Opin. Plant Biol. 10, 21-25.

Doust, A. N. (2017). "The effect of photoperiod on flowering time, plant architecture, and biomass in Setaria," in Genetics and Genomics of Setaria, eds A. Doust and X. Diao (Cham: Springer International Publishing), 197-210.

Doust, A. N., Devos, K. M., Gadberry, M. D., Gale, M. D., and Kellogg, E. A. (2004). Genetic control of branching in foxtail millet. Proc. Natl. Acad. Sci. U.S.A. 101, 9045-9050. doi: 10.1073/pnas.0402892101

Doust, A. N., Devos, K. M., Gadberry, M. D., Gale, M. D., and Kellogg, E. A. (2005). The genetic basis for inflorescence variation between foxtail and green millet (Poaceae). Genetics 169, 1659-1672. doi: 10.1534/genetics.104.035543

Doust, A. N., and Diao, X. (2017). Genetics and Genomics of Setaria. Switzerland: Springer International Publishing. doi: 10.1007/978-3-319-45105-3

Doust, A. N., and Kellogg, E. A. (2002). Inflorescence diversification in the panicoid "bristle grass" clade (Paniceae, Poaceae): evidence from molecular phylogenies and developmental morphology. Am. J. Bot. 89, 1203-1222. doi: 10.3732/ajb.89. 8.1203

Doust, A. N., and Kellogg, E. A. (2006). Effect of genotype and environment on branching in weedy green millet (Setaria viridis) and domesticated foxtail millet (Setaria italica) (Poaceae). Mol. Ecol. 15, 1335-1349. doi: 10.1111/j.1365-294X. 2005.02791.x

Doust, A. N., Kellogg, E. A., Devos, K. M., and Bennetzen, J. L. (2009). Foxtail millet: a sequence-driven grass model system. Plant Physiol. 149, 137-141. doi: 10.1104/pp.108.129627

Doust, A. N., Lukens, L., Olsen, K. M., Mauro-Herrera, M., Meyer, A., and Rogers, K. (2014a). Beyond the single gene: how epistasis and gene-byenvironment effects influence crop domestication. Proc. Natl. Acad. Sci. U.S.A. 111, 6178-6183. doi: 10.1073/pnas.1308940110

Doust, A. N., Mauro-Herrera, M., Francis, A. D., and Shand, L. C. (2014b). Morphological diversity and genetic regulation of inflorescence abscission zones in grasses. Am. J. Bot. 101, 1759-1769. doi: 10.3732/ajb.1400186

Doust, A. N., Mauro-Herrera, M., Hodge, J. G., and Stromski, J. (2017). The C4 model grass Setaria is a short day plant with secondary long day genetic regulation. Front. Plant Sci. 8:1062. doi: 10.3389/fpls.2017.01062

Doust, A. N., Penly, A. M., Jacobs, S. W., and Kellogg, E. A. (2007). Congruence, conflict, and polyploidization shown by nuclear and chloroplast markers in the monophyletic "bristle clade" (Paniceae, Panicoideae, Poaceae). Syst. Bot. 32, 531-544. doi: 10.1600/036364407782250670

Emily, S. C., Paul, C. W., James, S. G., and Jonathan, A. F. (2013). Redefining agricultural yields: from tonnes to people nourished per hectare. Environ. Res. Lett. 8:3.

Fahlgren, N., Feldman, M., Gehan, M. A., Wilson, M. S., Shyu, C., Bryant, D. W., et al. (2015). A versatile phenotyping system and analytics platform reveals diverse temporal responses to water availability in Setaria. Mol. Plant 8, 15201535. doi: 10.1016/j.molp.2015.06.005

Fan, X. K., Tang, S., Zhi, H., He, M. M., Ma, W. S., Jia, Y. C., et al. (2017). Identification and Fine mapping of SiDWARF3 (D3), a Pleiotropic Locus controlling environment-independent dwarfism in foxtail millet. Crop Sci. 57, 2431-2442. doi: 10.2135/cropsci2016.11.0952

Fang, X., Dong, K., Wang, X., Liu, T., He, J., Ren, R., et al. (2016). A high density genetic map and QTL for agronomic and yield traits in Foxtail millet [Setaria italica (L.) P. Beauv.]. BMC Genomics 17:336. doi: 10.1186/s12864-016-2628-z

Feldman, M. J., Paul, R. E., Banan, D., Barrett, J. F., Sebastian, J., Yee, M. C., et al. (2017). Time dependent genetic analysis links field and controlled environment phenotypes in the model C-4 grass Setaria. PLoS Genet. 13:e1006841. doi: 10. 1371/journal.pgen.1006841

Finlayson, S. A., Krishnareddy, S. R., Kebrom, T. H., and Casal, J. J. (2010). Phytochrome regulation of branching in Arabidopsis. Plant Physiol. 152, 19141927. doi: 10.1104/pp.109.148833 
Fukunaga, K., Domon, E., and Kawase, M. (1997). Ribosomal DNA variation in foxtail millet, Setaria italica (L.) P. Beauv., and a survey of variation from Europe and Asia. Theor. Appl. Genet. 95, 751-756. doi: 10.1007/s0012200 50621

Ghimire, K. H., Joshi, B. K., Gurung, R., and Sthapit, B. R. (2018). Nepalese foxtail millet Setaria italica (L.) P. Beauv. genetic diversity revealed by morphological markers. Genet. Resour. Crop Evol. 65, 1147-1157. doi: 10.1007/s10722-0170602-5

Glemin, S., and Bataillon, T. (2009). A comparative view of the evolution of grasses under domestication. New Phytol. 183, 273-290. doi: 10.1111/j.1469-8137.2009. 02884.x

Goff, S. A., Ricke, D., Lan, T. H., Presting, G., Wang, R. L., Dunn, M., et al. (2002). A draft sequence of the rice genome (Oryza sativa L. ssp japonica). Science 296, 92-100. doi: 10.1126/science. 1068275

Goron, T. L., and Raizada, M. N. (2015). Genetic diversity and genomic resources available for the small millet crops to accelerate a New Green Revolution. Front. Plant Sci. 6:157. doi: 10.3389/fpls.2015.00157

Hirano, R., Naito, K., Fukunaga, K., Watanabe, K. N., Ohsawa, R., and Kawase, M. (2011). Genetic structure of landraces in foxtail millet (Setaria italica (L.) P. Beauv.) revealed with transposon display and interpretation to crop evolution of foxtail millet. Genome 54, 498-506. doi: 10.1139/g11-015

Hodge, J. G., and Doust, A. N. (2017). "Morphological development of Setaria viridis from germination to flowering," in Genetics and Genomics of Setaria, eds A. Doust and X. Diao (Cham: Springer International Publishing), 161-175.

Hodge, J. G., and Kellogg, E. A. (2016). Abscission zone development in Setaria viridis and its domesticated relative, Setaria italica. Am. J. Bot. 103, 998-1005. doi: 10.3732/ajb.1500499

Holland, J. B. (2015). MAGIC maize: a new resource for plant genetics. Genome Biol. 16:163. doi: 10.1186/s13059-015-0713-2

Huang, P., and Feldman, M. (2017). "Genetic diversity and geographic distribution of north American Setaria viridis populations," in Genetics and Genomics of Setaria, eds A. Doust and X. Diao (Cham: Springer International Publishing), 45-59.

Huang, P., Feldman, M., Schroder, S., Bahri, B. A., Diao, X., Zhi, H., et al. (2014). Population genetics of Setaria viridis, a new model system. Mol. Ecol. 23, 4912-4925. doi: 10.1111/mec. 12907

Huang, P., Jiang, H., Zhu, C. M., Barry, K., Jenkins, J., Sandor, L., et al. (2017). Sparse panicle1 is required for inflorescence development in Setaria viridis and maize. Nat. Plants 3:17054. doi: 10.1038/nplants.2017.54

Huang, P., Shyu, C., Coelho, C. P., Cao, Y., and Brutnell, T. P. (2016). Setaria viridis as a model system to advance millet genetics and genomics. Front. Plant Sci. 7:1781. doi: 10.3389/fpls.2016.01781

Jia, J., Zhao, S., Kong, X., Li, Y., Zhao, G., He, W., et al. (2013a). Aegilops tauschii draft genome sequence reveals a gene repertoire for wheat adaptation. Nature 496, 91-95. doi: 10.1038/nature12028

Jia, G., Huang, X., Zhi, H., Zhao, Y., Zhao, Q., Li, W., et al. (2013b). A haplotype map of genomic variations and genome-wide association studies of agronomic traits in foxtail millet (Setaria italica). Nat. Genet. 45, 957-961. doi: 10.1038/ng. 2673

Jia, G., Shi, S., Wang, C., Niu, Z., Chai, Y., Zhi, H., et al. (2013c). Molecular diversity and population structure of Chinese green foxtail Setaria viridis (L.) Beauv. revealed by microsatellite analysis. J. Exp. Bot. 64, 3645-3655. doi: 10.1093/jxb/ ert198

Jiang, H., Barbier, H., and Brutnell, T. (2013). Methods for performing crosses in Setaria viridis, a new model system for the grasses. J. Vis. Exp. 1:80. doi: $10.3791 / 50527$

Jiang, H., Huang, P., and Brutnell, T. P. (2017). "Forward genetics in Setaria viridis," in Genetics and Genomics of Setaria, eds A. Doust and X. Diao (Cham: Springer International Publishing)), 303-322. doi: 10.1007/978-3-319-45105-3_18

Jones, M. (2004). "Between fertile crescents: minor grain crops and agricultural origins," in Traces of Ancestry: Studies in Honour of Colin Renfrew, ed. M. Jones (Cambridge: McDonald Institute for Archaeological Research), 127-135.

Jusuf, M., and Pernes, J. (1985). Genetic-variability of foxtail millet (Setaria-italica P Beauv) - electrophoretic study of 5 isoenzyme systems. Theor. Appl. Genet. 71, 385-391. doi: 10.1007/BF00251177

Kawase, M., and Sakamoto, S. (1984). Variation, geographical-distribution and genetic-analysis of esterase isozymes in foxtail millet, Setaria-italica (L) P-BEAUV. Theor. Appl. Genet. 67, 529-533. doi: 10.1007/BF00264899
Kellogg, E. A. (2015). Flowering Plants. Monocots: Poaceae. New York, NY: Springer International Publishing. doi: 10.1007/978-3-319-15332-2

Kellogg, E. A. (2017). "Evolution of Setaria," in Genetics and Genomics of Setaria, eds A. Doust and X. Diao (Cham: Springer International Publishing), 3-27. doi: 10.1007/978-3-319-45105-3_1

Kellogg, E. A., Aliscioni, S. S., Morrone, O., Pensiero, J., and Zuloaga, F. (2009). A phylogeny of Setaria (Poaceae, Panicoideae, Paniceae) and related genera based on the chloroplast gene ndhF. Int. J. Plant Sci. 170, 117-131. doi: 10.1086/ 593043

Kikuchi, K., Shyu, C., and Brutnell, T. P. (2017). "Transposon Tagging in Setaria viridis," in Genetics and Genomics of Setaria, eds A. Doust and X. Diao (Cham: Springer International Publishing), 323-342. doi: 10.1007/978-3-31945105-3_19

Kover, P. X., Valdar, W., Trakalo, J., Scarcelli, N., Ehrenreich, I. M., Purugganan, M. D., et al. (2009). A Multiparent advanced generation inter-cross to finemap quantitative traits in Arabidopsis thaliana. PLoS Genet. 5:e1000551. doi: 10.1371/journal.pgen.1000551

Kumari, K., Muthamilarasan, M., Misra, G., Gupta, S., Subramanian, A., Parida, S. K., et al. (2013). Development of eSSR-Markers in Setaria italica and their applicability in studying genetic diversity, cross-transferability and comparative mapping in millet and non-millet species. PLoS One 8:e67742. doi: 10.1371/ journal.pone.0067742

Lata, C., Bhutty, S., Bahadur, R. P., Majee, M., and Prasad, M. (2011). Association of an SNP in a novel DREB2-like gene SiDREB2 with stress tolerance in foxtail millet [Setaria italica (L.)]. J. Exp. Bot. 62, 3387-3401. doi: 10.1093/jxb/ err016

Lata, C., and Prasad, M. (2014). Association of an allele-specific marker with dehydration stress tolerance in foxtail millet suggests SiDREB2 to be an important QTL. J. Plant Biochem. Biotechnol. 23, 119-122. doi: 10.1007/s13562013-0193-y

Layton, D. J., and Kellogg, E. A. (2014). Morphological, phylogenetic, and ecological diversity of the new model species Setaria viridis (Poaceae: Paniceae) and its close relatives. Am. J. Bot. 101, 539-557. doi: 10.3732/ajb.1300428

Le Thierry d'Ennequin, M., Panaud, O., Toupance, B., and Sarr, A. (2000). Assessment of genetic relationships between Setaria italica and its wild relative S. viridis using AFLP markers. Theor. Appl. Genet. 100, 1061-1066. doi: $10.1007 / \mathrm{s} 001220051387$

Lee, G.-A. (2011). The transition from foraging to farming in prehistoric Korea. Curr. Anthropol. 52, S307-S329. doi: 10.1086/658488

Li, C., Yue, J., Wu, X., Xu, C., and Yu, J. (2014). An ABA-responsive DRE-binding protein gene from Setaria italica, SiARDP, the target gene of SiAREB, plays a critical role under drought stress. J. Exp. Bot. 65, 5415-5427. doi: 10.1093/jxb/ eru302

Li, H. W., Meng, C. J., and Liu, T. N. (1935). Problems in the breeding of millet [Setaria italica (L.) Beauv.]. J. Am. Soc. Agron. 27, 670-693. doi: 10.2134/ agronj1935.00021962002700120002x

Li, H. Y., and Yang, Y. F. (2008). Phenotypic plasticity of life history characteristics: quantitative analysis of delayed reproduction of green foxtail (Setaria viridis) in the Songnen Plain of China. J. Integr. Plant Biol. 50, 641-647. doi: 10.1111/j. 1744-7909.2008.00646.x

Li, L. F., and Olsen, K. M. (2016). "To have and to hold: selection for seed and fruit retention during crop domestication," in Current Topics in Developmental Biology, ed. V. Orgogozo (Cambridge, MA: Academic Press), 63-109. doi: 10. 1016/bs.ctdb.2016.02.002

Li, P., and Brutnell, T. P. (2011). Setaria viridis and Setaria italica, model genetic systems for the Panicoid grasses. J. Exp. Bot. 62, 3031-3037. doi: 10.1093/jxb/ err096

Li, W., Tang, S., Zhang, S., Shan, J., Tang, C., Chen, Q., et al. (2016). Gene mapping and functional analysis of the novel leaf color gene SiYGL1 in foxtail millet [Setaria italica (L.) P. Beauv]. Physiol. Plant. 157, 24-37. doi: 10.1111/ppl. 12405

Li, W., Zhi, H., Wang, Y.-F., Li, H.-Q., and Diao, X.-M. (2012). Assessment of genetic relationship of foxtail millet with its wild ancestor and close relatives by ISSR markers. J. Integr. Agric. 11, 556-566. doi: 10.1016/S2095-3119(12) 60042-2

Li, Y., Jia, J. Z., Wang, Y., and Wu, S. Z. (1998). Intraspecific and interspecific variation in Setaria revealed by RAPD analysis. Genet. Resour. Crop Evol. 45, 279-285. doi: 10.1023/A:1008600123509 
Lightfoot, E., Liu, X., and Jones, M. K. (2013). Why move starchy cereals? A review of the isotopic evidence for prehistoric millet consumption across Eurasia. World Archaeol. 45, 574-623. doi: 10.1080/00438243.2013.85 2070

Lin, Z., Li, X., Shannon, L. M., Yeh, C.-T., Wang, M. L., Bai, G., et al. (2012). Parallel domestication of the Shattering1 genes in cereals. Nat. Genet. 44, 720-724. doi: 10.1038/ng.2281

Ling, H. Q., Zhao, S., Liu, D., Wang, J., Sun, H., Zhang, C., et al. (2013). Draft genome of the wheat A-genome progenitor Triticum urartu. Nature 496, 87-90. doi: 10.1038/nature11997

Lü, H., Li, Y., Zhang, J., Yang, X., Ye, M., Li, Q., et al. (2014). Component and simulation of the 4,000-year-old noodles excavated from the archaeological site of Lajia in Qinghai. China. Chin. Sci. Bull. 59, 5136-5152. doi: 10.1007/s11434014-0663-1

Lü, H., Yang, X., Ye, M., Liu, K.-B., Xia, Z., Ren, X., et al. (2005). Millet noodles in Late Neolithic China. Nature 437, 967-968. doi: 10.1038/437967a

Lü, H., Zhang, J., Liu, K.-B., Wu, N., Li, Y., Zhou, K., et al. (2009). Earliest domestication of common millet (Panicum miliaceum) in East Asia extended to 10,000 years ago. Proc. Natl. Acad. Sci. U.S.A. 106, 7367-7372. doi: 10.1073/ pnas.0900158106

Martins, P. K., Ribeiro, A. P., Cunha, B. A. D. B. D., Kobayashi, A. K., and Molinari, H. B. C. (2015). A simple and highly efficient Agrobacteriummediated transformation protocol for Setaria viridis. Biotechnol. Rep. 6, 41-44. doi: $10.1016 /$ j.btre.2015.02.002

Masumoto, H., Takagi, H., Mukainari, Y., Terauchi, R., and Fukunaga, K. (2016). Genetic analysis of NEKODE1 gene involved in panicle branching of foxtail millet, Setaria italica (L.) P. Beauv., and mapping by using QTL-seq. Mol. Breed. 36:59. doi: 10.1007/s11032-016-0481-z

Matsumoto, T., Wu, J. Z., Kanamori, H., Katayose, Y., Fujisawa, M., Namiki, N., et al. (2005). The map-based sequence of the rice genome. Nature 436, 793-800. doi: 10.1038 /nature03895

Mauro-Herrera, M., and Doust, A. N. (2016). Development and genetic control of plant architecture and biomass in the panicoid grass. Setaria. PLoS One 11:e0151346. doi: 10.1371/journal.pone.0151346

Mauro-Herrera, M., Wang, X., Barbier, H., Brutnell, T. P., Devos, K. M., and Doust, A. N. (2013). Genetic control and comparative genomic analysis of flowering time in Setaria (Poaceae). G3, 283-295. doi: 10.1534/g3.112.005207

McMullen, M. D., Kresovich, S., Villeda, H. S., Bradbury, P., Li, H., Sun, Q., et al. (2009). Genetic properties of the maize nested association mapping population. Science 325, 737-740. doi: 10.1126/science. 1174320

McSteen, P. (2009). Hormonal regulation of branching in grasses. Plant Physiol. 149, 46-55. doi: 10.1104/pp.108.129056

Nadeem, F., Ahmad, Z., Wang, R., Han, J., Shen, Q., Chang, F., et al. (2018). Foxtail Millet [Setaria italica (L.) Beauv.] Grown under low nitrogen shows a smaller root system, enhanced biomass accumulation, and nitrate transporter expression. Front. Plant Sci. 9:205. doi: 10.3389/fpls.2018.00205

Nakayama, H., Afzal, M., and Okuno, K. (1998). ). Intraspecific differentiation and geographical distribution of Wx alleles for low amylose content in endosperm of foxtail millet, Setaria italica (L.) Beauv. Euphytica 102, 289-293. doi: 10.1023/A: 1018344819531

Nasu, H., Momohara, A., Yasuda, Y., and He, J. (2007). The occurrence and identification of Setaria italica (L.) P. Beauv. (foxtail millet) grains from the Chengtoushan site (ca. $5800 \mathrm{cal} \mathrm{B.P.)} \mathrm{in} \mathrm{central} \mathrm{China,} \mathrm{with} \mathrm{reference} \mathrm{to} \mathrm{the}$ domestication centre in Asia. Veg. Hist. Archaeobot. 16, 481-494. doi: 10.1007/ s00334-006-0068-4

Odonkor, S. E. (2015). Quantitative trait locus (QTL) Mapping Of Seed Weight, Pericarp Color, Bristling and Seed Shattering in Setaria. Master of Science, University of Georgia, Athens, GA.

Ongom, P. O., and Ejeta, G. (2017). Mating Design and genetic structure of a multiparent advanced generation inter-cross (MAGIC) population of Sorghum (Sorghum bicolor (L.) Moench). G3 8, 331-341. doi: 10.1534/g3.117.300248

Pandey, G., Misra, G., Kumari, K., Gupta, S., Parida, S. K., Chattopadhyay, D., et al. (2013). Genome-wide development and use of microsatellite markers for largescale genotyping applications in foxtail millet [Setaria italica (L.)]. DNA Res. 20, 197-207. doi: 10.1093/dnares/dst002

Paterson, A. H., Bowers, J. E., Bruggmann, R., Dubchak, I., Grimwood, J., Gundlach, H., et al. (2009). The Sorghum bicolor genome and the diversification of grasses. Nature 457, 551-556. doi: 10.1038/nature07723
Paterson, A. H., Lin, Y.-R., Li, Z., Schertz, K. F., Doebley, J. F., Pinson, S. R., et al. (1995). Convergent domestication of cereal crops by independent mutations at corresponding genetic loci. Science 269, 1714-1718. doi: 10.1126/science.269. 5231.1714

Peng, Y., Zhang, J., Cao, G., Xie, Y., Liu, X., Lu, M., et al. (2010). Overexpression of a PLD $\alpha 1$ gene from Setaria italica enhances the sensitivity of Arabidopsis to abscisic acid and improves its drought tolerance. Plant Cell Rep. 29, 793-802. doi: 10.1007/s00299-010-0865-1

Poncet, V., Martel, E., Allouis, S., Devos, K., Lamy, F., Sarr, A., et al. (2002). Comparative analysis of QTLs affecting domestication traits between two domesticated $\times$ wild pearl millet (Pennisetum glaucum L., Poaceae) crosses. Theor. Appl. Genet. 104, 965-975. doi: 10.1007/s00122-002-0889-1

Purugganan, M. D., and Fuller, D. Q. (2009). The nature of selection during plant domestication. Nature 457, 843-848. doi: 10.1038/nature07895

Qi, X., Xie, S., Liu, Y., Yi, F., and Yu, J. (2013). Genome-wide annotation of genes and noncoding RNAs of foxtail millet in response to simulated drought stress by deep sequencing. Plant Mol. Biol. 83, 459-473. doi: 10.1007/s11103-013-0104-6

Qie, L., Jia, G., Zhang, W., Schnable, J., Shang, Z., Li, W., et al. (2014). Mapping of quantitative trait locus (QTLs) that contribute to germination and early seedling drought tolerance in the interspecific cross Setaria italica $\times$ Setaria viridis. PLoS One 9:e101868. doi: 10.1371/journal.pone.0101868

Saha, P., and Blumwald, E. (2016). Spike-dip transformation of Setaria viridis. Plant J. 86, 89-101. doi: $10.1111 /$ tpj.13148

Saha, P., and Blumwald, E. (2017). "Spike-Dip transformation method of Setaria viridis," in Genetics and Genomics of Setaria, eds A. Doust and X. Diao (Cham: Springer International Publishing), 357-369. doi: 10.1007/978-3-31945105-3_21

Schnable, P. S., Ware, D., Fulton, R. S., Stein, J. C., Wei, F. S., Pasternak, S., et al. (2009). The B73 maize genome: complexity, diversity, and dynamics. Science 326, 1112-1115. doi: 10.1126/science.1178534

Schroder, S., Bahri, B. A., Eudy, D. M., Layton, D. J., Kellogg, E. A., and Devos, K. M. (2017). Genetic diversity and origin of North American green foxtail Setaria viridis (L.) Beauv. accessions. Genet. Resour. Crop Evol. 64, 367-378. doi: 10.1007/s10722-016-0363-6

Sebastian, J., Wong, M. K., Tang, E., and Dinneny, J. R. (2014). Methods to promote germination of dormant Setaria viridis seeds. PLoS One 9:e95109. doi: 10.1371/journal.pone.0095109

Sergusheva, E. A., and Vostretsov, Y. E. (2009). "The advance of agriculture in the coastal zone of East Asia," in From Foragers to Farmers: Papers in Honour of Gordon C. Hillman, ed. A. S. Fairbairn (Oxford: Oxbow Books), 205-219.

Studer, A. J., Schnable, J. C., Weissmann, S., Kolbe, A. R., Mckain, M. R., Shao, Y., et al. (2016). The draft genome of the C-3 panicoid grass species Dichanthelium oligosanthes. Genome Biol. 17:223. doi: 10.1186/s13059-016-1080-3

Swanton, C. J., Huang, J. Z., Deen, W., Tollenaar, M., Shrestha, A., and Rahimian, H. (1999). Effects of temperature and photoperiod on Setaria viridis. Weed Sci. 47, 446-453.

Tang, S., Li, L., Wang, Y., Chen, Q., Zhang, W., Jia, G., et al. (2017). Genotypespecific physiological and transcriptomic responses to drought stress in Setaria italica (an emerging model for Panicoideae grasses). Sci. Rep. 7:10009. doi: 10.1038/s41598-017-08854-6

Van Eck, J., and Swartwood, K. (2015). "Setaria viridis," in Agrobacterium Protocols, Vol. 1, ed. K. Wang (New York, NY: Springer), 57-67.

Van Eck, J., Swartwood, K., and Brutnell, T. (2011). Development of an Agrobacterium tumefaciens-mediated transformation method for Setaria viridis (Green Millet). In Vitro Cell. Dev. Biol. Anim. 47, S79-S79.

Van Eck, J., Swartwood, K., Pidgeon, K., and Maxson-Stein, K. (2017). "Agrobacterium tumefaciens-Mediated Transformation of Setaria viridis", in Genetics and Genomics of Setaria, eds A. Doust and X. Diao (Cham: Springer International Publishing), 343-356.

VanBuren, R., Bryant, D., Edger, P. P., Tang, H. B., Burgess, D., Challabathula, D., et al. (2015). Single-molecule sequencing of the desiccation-tolerant grass Oropetium thomaeum. Nature 527, 508-U209. doi: 10.1038/nature15714

Varshney, R. K., Shi, C. C., Thudi, M., Mariac, C., Wallace, J., Qi, P., et al. (2017). Pearl millet genome sequence provides a resource to improve agronomic traits in arid environments. Nat. Biotechnol. 35, 969-976. doi: 10.1038/nbt.3943

Vogel, J. P., Garvin, D. F., Mockler, T. C., Schmutz, J., Rokhsar, D., Bevan, M. W., et al. (2010). Genome sequencing and analysis of the model grass Brachypodium distachyon. Nature 463, 763-768. doi: 10.1038/nature08747 
Wang, C., Chen, J., Zhi, H., Yang, L., Li, W., Wang, Y., et al. (2010). Population genetics of foxtail millet and its wild ancestor. BMC Genet. 11:90. doi: 10.1186/ 1471-2156-11-90

Wang, J., Wang, Z., Du, X., Yang, H., Han, F., Han, Y., et al. (2017). A highdensity genetic map and QTL analysis of agronomic traits in foxtail millet [Setaria italica (L.) P. Beauv.] using RAD-seq. PLoS One 12:e0179717. doi: 10.1371/journal.pone.0179717

Wang, R.-L., Wendel, J. F., and Dekker, J. H. (1995a). Weedy adaptation in Setaria spp. II. Genetic diversity and population genetic structure in S. glauca, S. geniculata, and S. faberii (Poaceae). Am. J. Bot. 82, 1031-1039. doi: 10.3732/ ajb.89.3.410

Wang, R. L., Wendel, J. F., and Dekker, J. H. (1995b). Weedy adaptation in Setaria Spp.1. isozyme analysis of genetic diversity and population genetic-structure in Setaria-viridis. Am. J. Bot. 82, 308-317. doi: 10.3732/ajb.89.3.410

Wang, Y., Zhi, H., Li, W., Li, H., Wang, Y., Huang, Z., et al. (2009). A novel genome of $\mathrm{C}$ and the first autotetraploid species in the Setaria genus identified by genomic in situ hybridization. Genet. Resour. Crop Evol. 56, 843-850. doi: 10.1186/1471-2164-14-244

Wang, Z. M., Devos, K. M., Liu, C. J., Wang, R. Q., and Gale, M. D. (1998). Construction of RFLP-based maps of foxtail millet, Setaria italica (L.) P. Beauv. Theor. Appl. Genet. 96, 31-36. doi: 10.1007/s001220050705

Wheeler, T., and von Braun, J. (2013). Climate change impacts on global food security. Science 341, 508-513. doi: 10.1126/science.1239402

Xiang, J. S., Tang, S., Zhi, H., Jia, G. Q., Wang, H. J., and Diao, X. M. (2017). Loose Paniclel encoding a novel WRKY transcription factor, regulates panicle development, stem elongation, and seed size in foxtail millet Setaria italica (L.) P. Beauv. PLoS One 12:e0178730. doi: 10.1371/journal.pone.0178730

Xue, C. X., Zhi, H., Fang, X. J., Liu, X. T., Tang, S., Chai, Y., et al. (2016). Characterization and Fine mapping of SiDWARF2 (D2) in foxtail millet. Crop Sci. 56, 95-103. doi: 10.2135/cropsci2015.05.0331

Yang, J., Thames, S., Best, N. B., Jiang, H., Huang, P., Dilkes, B. P., et al. (2018). Brassinosteroids modulate meristem fate and differentiation of unique inflorescence morphology in Setaria viridis. Plant Cell 30, 48-66. doi: 10.1105/ tpc. 17.00816

Yang, N., Xu, X. W., Wang, R. R., Peng, W. L., Cai, L., Song, J. M., et al. (2017). Contributions of Zea mays subspecies mexicana haplotypes to modern maize. Nat. Commun. 8:1874. doi: 10.1038/s41467-017-02063-5
Yang, X., Wan, Z., Perry, L., Lu, H., Wang, Q., Zhao, C., et al. (2012). Early millet use in northern China. Proc. Natl. Acad. Sci. U.S.A. 109, 3726-3730. doi: 10.1073/pnas.1115430109

Yu, J., Hu, S., Wang, J., Wong, G. K., Li, S. G., Liu, B., et al. (2002). A draft sequence of the rice genome (Oryza sativa L. ssp indica). Science 296, 79-92.

Zhang, G., Liu, X., Quan, Z., Cheng, S., Xu, X., Pan, S., et al. (2012). Genome sequence of foxtail millet (Setaria italica) provides insights into grass evolution and biofuel potential. Nat. Biotechnol. 30, 549-554. doi: 10.1038/ nbt. 2195

Zhang, H. Y., Guo, P. Y., Wang, Y. G., Yuan, X. Y., Dong, S. Q., Song, X. E., et al. (2017). Assessment of male sterility and antioxidant enzyme activities induced by the chemical hybridization agent SQ-1 in foxtail millet (Setaria italica). Emirates J. Food Agric. 29, 212-221. doi: 10.9755/ejfa.201610-1530

Zhang, K., Fan, G., Zhang, X., Zhao, F., Wei, W., Du, G., et al. (2017). Identification of QTLs for 14 agronomically important traits in Setaria italica based on SNPs generated from high-throughput sequencing. G3 7, 1587-1594. doi: 10.1534/g3. 117.041517

Zhang, S., Tang, C., Zhao, Q., Li, J., Yang, L., Qie, L., et al. (2014). Development of highly polymorphic simple sequence repeat markers using genome-wide microsatellite variant analysis in Foxtail millet [Setaria italica (L.) P. Beauv.]. BMC Genomics 15:78. doi: 10.1186/1471-2164-15-78

Zhu, C., Yang, J., and Shyu, C. (2017). Setaria comes of age: meeting report on the second international Setaria genetics conference. Front. Plant Sci. 8:1562. doi: $10.3389 /$ fpls.2017.01562

Conflict of Interest Statement: The authors declare that the research was conducted in the absence of any commercial or financial relationships that could be construed as a potential conflict of interest.

Copyright (C) $2018 \mathrm{Hu}$, Mauro-Herrera and Doust. This is an open-access article distributed under the terms of the Creative Commons Attribution License (CC BY). The use, distribution or reproduction in other forums is permitted, provided the original author(s) and the copyright owner are credited and that the original publication in this journal is cited, in accordance with accepted academic practice. No use, distribution or reproduction is permitted which does not comply with these terms. 